\title{
Interfaces e interlocuções: os congressos de ciências sociais em saúde
}

\author{
Interfaces and interlocutions: \\ the social sciences on health congresses
}

M ara H. de Andréa Gomes 1

Paulete Goldenberg 1

Abstract This text describes the recent trajectory of the social sciences congresses on health; from the historical conjuncture of the insertion of social sciences in the medicine colleges curricula to the foundation of the Brazilian Association of Post-graduation Studies in Collective H ealth (ABRASCO). To account for this description, the problem axis - the individual-society relation - was taken as reference; as foundation mark not only of the social sciences but also of the collective health. In this perspective, the congresses subjects were retaken as indicatives of the area foundation marks and the explanation tendencies, by signing those present in all of them and the emergent questions. By this mean, we thought the collective health constitution as a tense field shared not only by social and historical "nature", but also by the possibility of reflections on the interfaces among the different sciences which compose them, and the congresses, as opportunities for interlocutions among them. Key words Individual-society relation, Fields of knowledge, Social sciences in health
Resumo Este artigo descreve a trajetória re cente dos congressos de ciências sociais em saúde, a partir da conjuntura histórica de inserção das ciências humanas nos currículos das faculdades de medicina, até a fundação da Associação Brasileira de Pós- Graduação em Saúde Coletiva (Abrasco). Para dar conta dessa descrição, tomamos como referência um eixo problematizador - a relação indivíduo-sociedade - como questão fundante não só das ciências sociais como da saúde col etiva. Com esta perspectiva de fundo, retomamos o temário dos congressos como indicati vos das questões balizadoras da área e das tendências de explicações, assinalando aquelas presentes em todos eles e as questões emergentes. N esta aproximação, pensamos a constituição da saúde coletiva como tenso campo compartilhado, não só por "natureza" social e histórica, como pela possibilidade de refletir sobre as interfaces entre as diversas ciências que o compõem, e os congressos como momentos de interlocuções en tre elas.

Palavras-chave Relação indivíduo-sociedade, Campos de conhecimento, Ciências sociais em saúde

\footnotetext{
1 Departamento de M edicina Preventiva da Unifesp, Escola Paulista de M edicina. Rua Pedro Toledo 675, 04039-032, São Paulo SP. maga@medprev.epm.br
} 
N ão deixa de provocar certa estranheza aos nossos ouvidos uma expressão bastante corrente, segundo a qual a epidemiologia "não lida com indivíduos, mas com a população", ou, pelo mesmo processo de abstração, a expressão que afirma que a clínica "só tem olhos para o indivíduo". A estranheza está mais no fato de que ambas as expressões transmitem convicções incorporadas, arraigadas e retransmitidas, do que no fato de que realmente assi $m$ procedem. $M$ as sem se dar conta de que procedem assim, por meio de abstrações...

\section{Introdução}

O convite para escrever este artigo estava mais diretamente relacionado a uma exposição sobre a real ização dos congressos de ciências sociais em saúde. Começamos por recuperar o percurso de criação da área através das tentativas de alinhavar as interfaces com o campo da saúde, concomitantemente ao registro do seu processo de institucionalização nos primeiros locais nos quais ocorreu: as escolas médicas e, nelas, nos departamentos de medicina preventiva e social.

Com esse procedimento - a recuperação desse processo em direção à realização de eventos como encontros e congressos - , chegaríamos ao registro do seu desenvolvimento, por meio de uma escrita que nos ajudasse a deslizar no percurso até o seu ápice: os congressos. Ao mesmo tempo, buscamos arrolar os temários desses eventos, também numa perspectiva "desenvolvimentista", como se quiséssemos mostrar "viram como crescemos?"

Ledo engano, tanto de uma parte como de outra. Engano decorrente da própria intenção tal como fora inicialmente pensada. N osso propósito, ao apontar o quadro de desenvolvimento do campo por meio dos eventos que realiza e do público que a eles aflui, tanto do ponto de vista da quantidade como do ponto de vista da diversi dade temática e profissional, está balizado pela suposição de que esse seria um critério indicativo de "uma" modalidade de exposição da riqueza da área: idéias verbalizadas ou escritas e produtos e subprodutos de todos os tipos de divulgação científica.

Os elencos dos temas apontam, sem dúvida, para uma ampliação do campo, apresentando problemas de investigação mais diversificados (e de público também, portanto), abarcando profissões diferenciadas. É claro que do ponto de vista da realização de eventos, essa amplia- ção tem um sinal positivo. M as como cientistas sociais e "humanos" não podemos nos furtar dever aí algo passível de problematização. E assim, procuramos torná-lo problemático à nossa maneira.

Em primeiro lugar, se quisermos indicar algum desenvolvimento através do expediente de realização de congressos (cujo mérito não épequeno, como reconhecemos sem dificuldade), talvez esse não seja o critério mais adequado, em vista das mais complicadas estratégias aí envolvidas. Diversificação de temas pode indicar também maior abrangência de questões problematizadas, a partir de um ou mais campos de conhecimento. Pode indicar mais: a complexidade envolvida na abordagem de temas cada vez mais "abrangenciáveis", ou, por outro ângulo, cada vez mais específicos e fragmentados. Ao nos depararmos com a ampliação dos temas elencados, nossa preocupação passou a ser a de buscar os possíveis "padrões que ligam" toda a produção e os produtos (Bateson, 1986), pois haveria de havê los, mesmo que não conseguíssemos reconhecêlos de imediato.

De fato, podemos construir critérios de "liga" com alguma facilidade e com certa dose de arbitrariedade, até por portarem, nos próprios títulos dos trabal hos enviados/apresentados/ publicados, termos comuns a transitar por muitos deles. Termos - apenas termos - em geral, contemporâneos a certas maneiras de tratar os temas. Estaríamos autorizadas a estabelecer ligas substantivas entre eles? Tarefa tentadora, mas adiável para outra ocasião.

\section{0 núcleo das interfaces?}

Desde a versão de 1939 do artigo "A sociedade dos indivíduos", Norbert Elias (1994) retomava o caráter tenso dessa relação indivíduo-sociedade para a sociologia ou antropologia (conforme o país, segundo ele): Existe hoje uma padronização muito difundida da auto-imagem que induz o indivíduo a se sentir e pensar assim: Estou aqui, inteiramente só; todos os outros estão lá, fora de mim; e cada um deles segue seu caminho, tal como eu, com um eu interior que é seu eu verdadejro, seu puro "eu", e uma roupagem externa, suas relações com as outras pessoas (1994).

Para Elias, essa atitude perante si mesmo e os outros, que parece natural e óbvia àqueles que a adotam, não é uma coisa nem outra. É um conflito no interior do indivíduo, essa "privatização" ou exclusão de certas esferas de vida 
da interação social, e a associação delas com o medo socialmente instilado sob a forma de vergonha e embaraço, por exemplo, que levam o indivíduo a achar que, "dentro" desi, ele éalgo que existe intei ramente só, sem relacionamento com os outros, eque só "depois" se relaciona com os outros, "do lado de fora" (1994).

Por mais autêntica e verdadeira que fosse essa idéia, afirma Elias, ela é uma expressão sumamente inadequada da verdadei ra relação existente entre os seres humanos. (...) E mais, a maneira como a sociedade promove a adaptação do indivíduo a suas funções adultas acentua... a cisão e a tensão internas a seu psiquismo (N orbert Elias, 1994).

Onde está a tensão? N aquilo que, para esse autor, torna especialmente difícil o condicionamento do indivíduo: não apenas o alto grau de controle e transformação dos instintos, como também as limitações e a especialização impostas pelas funções adultas, a intensidade da competição e as ten sões entre os vários grupos. Daí o sentimento de que, para manterem suas posições na rede humana, tentando conformar-se ao avanço da divisão das funções, os indivíduos devem deixar fenecer sua verdadeira natureza; nessa situação, com freqüência parece ao indivíduo que seu verdadeiro eu, sua alma, está trancafiado em algo alheio e externo, chamado "sociedade", como que numa cela (N orbert Elias, 1994).

Para Elias, o valor da concepção subjacente a essas idéias (como objeto da psicologia ou da sociologia), como "oposições", está no fato de constituírem expressão de determinado estágio histórico da rede humana e da forma correspondente de autoconsciência humana, mas deixa de ser assim valorizado quando o campo de investigação é ampliado. Por intermédio desse autor, estamos retomando a reflexão sobre a natureza tensa dessa relação não só para as ciências sociais, mas exatamente para o ponto de intersecção com saúde, expresso como campo "da" saúde (como al go que estaria "fora" dos demais "sociais"). 0 que nos coloca em plena intersecçãoaproximação, para seguir a trilha do autor, portanto, é a natureza ampliada desse campo, sobretudo quando associado, de maneira mais ou menos íntima e para efeito do que estamos considerando, à expressão síntese em torno da qual todos gravitamos: "saúde coletiva". Assim, ao tomarmos o conjunto de termos "ciências sociais em saúde", estamos tentando nos colocar a todos num mesmo campo. Campo tenso é verdade, uma vez que essa tensão, sendo constitutiva de ambos, deve ser constituinte da intersecção.
Nossa escolha pela noção de campo está norteada pela conhecida formulação de Bourdieu, que o entende... ao mesmo tempo como campo de forças e campo de lutas que visam transformar esse campo de forças (...) na sua relação com a noção de habitus... [como] sistemas de disposições socialmente constituídos. Em suas diversas pesquisas sobre educação e o sistema universitário francês, esse autor define como "campo científico" um sistema de relações objetivas entre posições adquiridas (em lutas anteriores)... o lugar, o espaço de jogo de uma luta concorrencial. 0 que está em jogo justamentenessa luta é o monopólio da autoridade científica definida, de maneira inseparável, como capacidade técnica e poder social (...) (Ortiz, 1994).

Para esboçar o modo como vemos esse esforço de indicar um ponto de intersecção (não o único, evidente) e tentar relacioná-lo com a noção de campo, devemos levar em conta mais uma orientação de Elias, segundo a qual (...) as relações interpessoais nunca podem ser expressas em simples formas espaciais. Esteéum modelo estático. Talvez ele atenda um pouco melhor a seu objetivo se imaginarmos a rede em constante movimento, como um tecer e destecer ininterrupto das ligações. (...) Esse alto grau de maleabilidade e adaptabilidade das funções relacionais humanas é, por um lado, uma precondição para a estrutura das relações entre as pessoas ser tão mais variável do que entre os animais... aqui está a base para a historicidade fundamental da sociedade humana (N orbert Elias, 1994).

$E$, à guisa de resumo de seus pressupostos, devemos considerar que as estruturas da psique humana, as estruturas da sociedade humana eas estruturas da história humana são indissociavelmente complementares, só podendo ser estudadas em conjunto. Elas não existem e se movem na realidade com o grau de isolamento presumido pelas pesquisas atuais. Formam, ao lado de outras estruturas, o objeto de uma única ciência humana. (...) o entrelaçamento de suas atividades dá origem a leis e estruturas de um tipo especial. Justamente por essa razão, acionam-sena rede mecanismos automáticos de mudança, transformações históricas, que não têm origem no aparelho reflexo humano hereditário, nem tampouco - vistos como um todo tal como efetivamente ocorrem - são desejados ou planejados por pessoas, isoladas, embora sejam tudo menos caóticos. Justamente por isso, o irrevogável entrelaçamento dos atos, necessidades, idéias e impul sos de muitas pessoas dá origem a estruturas e transformações estruturais numa ordem e direção especí- 
ficas que não são simplesmente "animais", "naturais" ou "espirituais", nem tampouco "racionais" ou "irracionais", mas sociais. U ma esfera econômica de interconexões não surge excl usi vamente... pelo fato de terem os seres humanos que satisfazer sua necessi dade de comer (...) As redes econômicas, no sentido humano, surgem apenas porque a auto-regulação humana em relação a outras coisas e seres não está automaticamente restrita, em igual medida, a canais relativamente estreitos. U ma das precondições da economia no sentido humano é o caráter singularmente psicológico do controle comportamental humano (N orbert Elias, 1994).

Por este motivo, Elias tem a convicção de que todas as tentativas de explicar... regularidades sociais a partir de regularidades biológicas ou de seus padrões, todos os esforços de transformar a ciência social numa espécie de biologia ou numa parte das outras ciências naturais revelam-se inúteis (1994).

Há, ainda, mais um aspecto que merece ser registrado por referência ao pensamento desse autor. Caso, em meio a tantas citações, ainda não tenhamos conseguido explicitar o significado do termo "rede" para Elias, não é demais afirmar que diferentemente do sentido atual, ele denota a totalidade da relação entre indivíduo e sociedade. No seu interior, as associações são criadas como que desempenhando uma ordem invisível, sem esquecermos que, para ele, 0 termo "todo" se referea algo mais ou menos harmonioso. M as a vida social dos seres humanos é repleta de contradições, tensões e explosões. (...) A vida dos seres humanos em comunidade certamente não é harmoniosa. $M$ as, se não a harmonia, ao menos a palavra "todo" evoca-nos a idéia de alguma coisa completa em si, de uma formação de contornos nítidos, de uma forma perceptível euma estrutura discernível e mais ou menos visível. As sociedades, porém, não têm essa forma perceptível. (...) consideradas como totalidades, são sempre mais ou menos incompletas: de onde quer que sejam vistas, continuam em aberto na esfera temporal em direção ao passado e ao futuro (N orbert Elias, 1994).

Se aceitarmos essas premissas e a dinâmica da relação indivíduo-sociedade a partir da qual cada termo se afirma por referência ao outro, sendo, nessa medida, indissociáveis, o termo coletivo deixa de ser mais um aposto da saúde. Ao contrário, significa-o - com um conteúdo tenso. Indissociáveis porque complementares, o que impossibilita suprimir qualquer um dos termos da relação (como apontamos no início à guisa de epígrafe). Pode ser uma artimanha perigosa tentar negar, recusar, refutar o "plano individual", "biomédico", da "clínica” em nome da supremacia do "social", "coletivo" da saúde. Pois contorna-se a tensão aí existente simplesmente suprimindo um dos termos da relação e, assim procedendo, tenta-se desfazer a própria relação que realiza ambos. Além disso, essa noção de todo-totalidade inclui tensões e contradições numa perspectiva bastante diferente daquela maneira de apropriação do materialismo histórico, muito em voga num certo período dessas interfaces, que lhe conferia um aspecto mais "totalitário" do que propriamente "totalizável".

Também não estamos querendo afirmar que os termos não podem ser focalizados separadamente, cada qual com referenciais que lhe são mais próprios e apropriados às relações que se pretende compreender, explicar e, dependendo da prática em questão, intervir - mas sem perder de vista sua natureza relacional. É evidente que não estamos propondo a retomada dessa relação em cada estudo que se faça no campo da saúde coletiva. Queremos apenas relembrar que as ciências sociais em saúde compartilham essa "tensão essencial" (parafraseando uma obra de Thomas Kuhn), daí acreditarmos na possibilidade de constituirmos um campo comum, entendendo-o à maneira de Bourdieu. Que fique claro, também, que não estamos propondo a formação de uma ciência ou teoria geral, e sim de um campo de intelecção e práticas que compartilham referenciais históricos, teóricos e epistemológicos, cada qual com suas especificidades e suas próprias tensões - algumas essenciais outras nem tanto, como bem sabemos.

Daí atribuirmos a Bodstein (1992) o arrojo de apontar o que não só viria a ser tema do congresso da Abrasco em 2000 ("O sujeito da saúde coletiva"), como também a forma com que criticou a redução da análise de quaisquer processos ao processo de acumulação de capital e reprodução da força de trabalho. Seus apontamentos trouxeram para o campo da saúde questões relacionadas ao sujeito, tal como vinham sendo debatidas por cientistas sociais europeus a partir de Weber, único autor da "tríade" clássica das ciências sociais que considera a dimensão subjetiva da ação "social". D essa maneira, sistematizou a reflexão em direção à reapropriação do tema da subjetividade pela sociologia e a necessidade desta dimensão ser considerada na sua intersecção com o campo da saúde. Temas como identidade, valorização da subje- 
tividade, consideração do imaginário e da cultura como instâncias mediadoras desta intersecção, passam a ser abordados sem a pecha de "ismos" (econômico, biológico, psicológico...). Ao mesmo tempo, constituiu um apelo dirigido aos cientistas sociais da área, para que acompanhassem a reflexão intelectual produzida nas ciências sociais tanto aqui como além das fronteiras nacionais. E assim vínhamos fazendo, embora nem sempre relacionando com saúde.

$M$ as de onde essa reapropriação? Por quais percursos intelectuais ela "vingou" nesse momento, nem antes nem depois? Por quê? Embora nosso intuito não seja apontar "novas questões", tentamos, com essas considerações anteriores, seguir o apelo-convite de Bodstein em torno de outras abordagens para aquela que talvez seja a questão mais antiga e fundante da sociologia: a tensão constitutiva da relação indivíduo-sociedade.

A importância de seguir este percurso através de um relato acerca dos congressos realizados nessa área reside justamente no fato de promoverem interlocuções. 0 que torna ainda mais interessante o mapeamento dos temários e seus participantes éuma constatação, pelo menos intrigante, a partir da qual podemos pensar hipóteses especulativas: nesses momentos congressuais, a reflexão que estamos retomando vem sendo proposta e apresentada mais por epidemiologistas ou outros profissionais do campo biomédico, do que por cientistas sociais.

De qualquer modo, esta tentativa pode ser uma oportunidade para retomarmos algumas questões que nos põem - ciências sociais e saúde - em complementaridade de reflexão. Um momento que se presta a enfatizar a necessidade de elaborar outros percursos para aprofundarmos as interfaces. É passado o momento de auto-afirmação; existimos, e demos parcelas consideráveis de contribuição para a reflexão do campo. Que tal seria retomar também propostas que não desenvolvemos, já que a própria conjuntura histórica vem se encarregando de indicar questões emergentes? Talvez essa seja uma das tarefas que as ciências sociais em saúde tenham que enfrentar.

\section{Momentos de interlocuções: os congressos}

Tentemos, pois, elaborar um exercício de mapeamento dos temas a partir desta aproximação, não sem antes apresentar o seu contexto.
Comentar a realização dos congressos de ciências sociais em saúde inaugurados na década de 1990 requer ainda outros cuidados para não cairmos na tentação das nostal gias, das apologias e dos ressentimentos-lamúrias a que podem facilmente nos conduzir.

$M$ as nada impede que os consideremos a partir da própria trajetória da institucionalização dessa área de conhecimentos no âmbito da saúde. N unes $(1992,1995)$ e seus seguidores Canesqui (1998), M arsiglia \& Spinelli (1995) e M inayo (1997) têm sido os autores mais recorridos quando buscamos os registros dessa trajetória, não só do ponto de vista cronológico, mas sobretudo temático e analítico. Por intermédio desses registros, podemos afirmar, sem medo de incorrer em graves discrepâncias históricas, que a inserção institucional das ciências sociais nessa área se fez presente na América Latina especialmente a partir da Segunda Guerra, sob inspiração americana, mais particularmente da Escola de Chicago (Limongi, 1989) e suas temáticas relacionadas à doença e à prática médica orientada para a relação médico-paciente - aspectos então considerados desordenados em vista das transformações sociais recentes.

A preocupação dessa escola com os comportamentos desviantes causadores de desordem e desorganização em novas formas de sociabilidade - considerando a rápida expansão urbano-industrial como pano de fundo das transformações então em curso - ajudou a embasar uma certa perspectiva comportamentalista. Essa influência também se fez sentir desde os seminários realizados pela 0 pas em diversas cidades da América Latina e do Brasil, voltados para o ensino e metodologia no âmbito da medicina preventiva e social. Era o momento de reordenação política e econômica das nações que, no bojo do chamado movimento preventivista, realizava a crítica ao biologicismo do ensino, introduzindo também a pregação da estratégia didático-pedagógica de maior aproximação com o aluno e deste com a "realidade".

Por outro lado, a influência dos pressupostos da Escola de Chicago nessa aproximação incluía a consideração do homem como ser biopsicossocial numa perspectiva também "ecológica", que preconizava o modelo da história natural das doenças. Do ponto de vista metodológico, uma das propostas da escola incluía a opção pelo interacionismo simbólico para responder a uma dupla exigência: valorizar a atuação das ciências sociais nas pesquisas de caráter in- 
tervencionista que realizava e, na medida em que relações sociais eram vistas como "fenômenos" e a sociedade era considerada "entidade", um de seus fundadores (G. H. M ead) acreditava que a inserção da dimensão simbólica permitiria maior possibilidade de intervenção nos fenômenos de desagregação psíquica e social (Pierson, 1948; Vila N ova, 1998).

A importância desse movimento para o tema que estamos tratando está no fato de ter fundamentado a introdução dos cursos de ciências da conduta (e, junto com elas, a incorporação de cientistas sociais), ao lado da epidemiologia e da bioestatística, nos currículos dos departamentos de medicina preventiva e social queiam se inaugurando nas graduações médicas.

As diferentes trajetórias institucionais de incorporação das ciências sociais no campo da saúde foram tensas como tende a ser "a chegada de estranhos", sobretudo quando partem de determinações externas ao ambiente institucional ou mesmo de um departamento. As programações e a participação do conjunto de docentes das unidades departamentais acomodaram-se conforme as possibilidades existentes nos ambientes institucionais. Sem que tivessem deixado de estar presentes na atual idade, Nunes relembra os temas desta etapa inicial: alguns preocupados com o ensino, outros com a medicina tradicional, outros ainda com os estudos demográficos e de comunidade e, por último, os relacionados aos serviços. Não podemos deixar de mencionar, neste temário, esforços localizados de discutir a dimensão cultural na perspectiva antropológica, tais como a emergência da capacidade de simbolização, o conceito de cultura, a relação da cultura com o meio ambiente, relativismo e etnocentrismo, relação entre cultura e estrutura social.

Raros, no entanto, eram os autores que alinhavavam as relações teórico-epistemológicas entre esses temas, tanto no interior das próprias ciências sociais na sua relação com a saúde, como uma dentre elas e o campo exposto para análise. A este temário viria somar-se a preocupação não menos constitutiva das ciências sociais: a dinâmica da desigualdade. Também esta foi abordada, mas por intermédio de pesquisas e estudos de questões nutricionais, de emprego e desemprego, transporte, habitação e moradia etc., com um caráter descritivo (o que não é pouco) mais do que de elaboração teórico-fiIosófica, propriamente (o que seria mais desejável). No entanto, na ausência de pressupostos consolidados para dar conta deste empreendi- mento, desde aquel e momento é possível perceber 0 esforço de estabelecer conexões e interfaces entre as ciências sociais e o campo da saúde. Já se anunciava a promessa de aprofundamento dessas questões, do ponto de vista de um temário indicado pelas ciências sociais. Esta, talvez, constitua uma marca das possibilidades de elaboração das interfaces almejadas, desenvolvidas com o correr dos anos por meio de intensa interlocução e familiarização com profissionais da área da saúde.

Quando a O pas, acompanhando a linha do Encontro de Cuenca em 1972, apoiou a proposta da medicina comunitária indicando a valorização da saúde da família, assistimos à "coincidência" com a decisão de se repensar aquelas questões das ciências sociais nesta área sob a vertente do materialismo histórico. A busca de model os centrados na abordagem histórico-estrutural, "aplicados" aqui e ali quase mecanicamente, levou muitos cientistas sociais a considerar saúde e doença processos sim, porém sociais mais do que biológicos, num desenrolar de "negações" dirigidas a "superações" do modelo de organização das práticas e de formação de recursos humanos. A partir de então, a sociologia, mais do que a antropologia e a psicologia, foi imbuída de uma nova "missão", justificável é importante também ressaltar - pelas dificuldades que o continente atravessava. E também não deixou de promover um aprofundamento substantivo, mesmo quando simplesmente negava, ao descartar, as dimensões biológica e individual que, afinal, eram os motes para a construção de interfaces.

Felizmente a história dá chances para acasos e desdobramentos não intencionados, prega algumas peças para aqueles que se apegam a rígidas determinações. Se há al guma linearidade nesses movimentos, podemos buscá-la nas brechas e possibilidades para suas reconstruções em outras bases teórico-epistemológicas.

A partir dos anos 70 as universidades brasileiras tiveram que implantar a reforma universitária, sendo importante lembrar o fato de que esta mesma proposta propugnava a inclusão de cursos das "humanidades" em todas as áreas de formação. Assim, diversificaram-se ou incluíram-se disciplinas, ea presença de profissionais das "humanas" espalhou-se pelas faculdades, cabendo aos cientistas sociais (Consorte, 1984) (sociólogos e/ou antropólogos a depender das instituições) inseridos naquele momento o papel de "desenvolver a consciência crítica da realidade". Claro que a "realidade" aí era a que a re- 
forma considerava como tal, não menos reificada, todavia, por alguns cientistas sociais.

$\mathrm{Na}$ conjuntura nacional vivida à entrada dos anos 70, assistíamos a uma forte repressão política nas universidades e fora delas, ao mesmo tempo em que a estrutura curricular das escolas médicas passava por reformas, dentre as quais a citada inclusão das ciências sociais nos departamentos de medicina preventiva e social. Pelo lado da repressão, essa institucionalização ajudou a ganhar adeptos, a resistir e a aprofundar a reflexão crítica. Pelo lado da estrutura curricular, as ciências sociais já então institucionalizadas, e contanto com o "alinhamento" de certas correntes de pensamento político existentes também no campo biomédico, estiveram às voltas com a crítica ao "modelo biomédico da clínica", substituindo, com al guma teorização, a determinação biológica pela determinação social. Um e outro lado, de qualquer forma, estava empenhado na construção de um modelo de assistência em saúde pública que promovesse a ampliação dos direitos sociais e civis.

Verso e reverso de um mesmo processo, de senvolveram esquemas de reflexão que levaram para as escolas médicas o que já ocorria fora delas: a politização da medicina e dos modelos de ensino e cuidado. Não foi uma tarefa específica dos cientistas sociais, óbvia e evidentemente, mas em várias instituições talvez não tivesse ocorrido sem sua coadjuvação. No Rio de Janeiro e em São Paulo mais especialmente, sem querer desconsiderar as outras regiões do país, os movimentos dos médicos residentes e dos médicos sanitaristas, bem como a atuação dos sindicatos dos médicos nesses estados (o de São Paulo foi o primeiro sindicato a apoiar as greves de 78/79 da região do $A B C$ ), ajudaram a promover o que foi considerado um marco de mudança de conjuntura política no país, desembocando, anos mais tarde, no movimento das Diretas Já.

Da abertura política à Constituição "cidadã", passando pela elaboração de políticas locais de reorganização dos serviços já real izadas na área da saúde (M ontes Claros, PIASS, PAIS-AIS, Prev-Saúde, Conasp), eas experiências de aglutinação de forças (sendo o Cebes o grande catalisador do momento), à criação da Abrasco no começo da década de 1980, constituem etapas, por assim dizer - nessa tentativa de recuperação que não deixa de ser linear - que ajudaram a congregar interesses em torno dos quais professores, profissionais de saúde, técnicos e estudantes se viram debruçados: 0 ideário de demo- cratização social, sobretudo de acesso a serviços de saúde, consubstanciado no movimento da reforma sanitária.

Q uando se escancaravam as fraudes da Previdência Social concomitantemente ao fortalecimento deste movimento, a reflexão ampliouse e ao mesmo tempo se especificou numa dimensão política. É possível que a inserção da ciência política tenha ocorrido mais "tardiamente" não por mera casualidade, mas também ajudou a arrematar o processo de interlocução intelectual e disciplinar que apontava para a ampliação das interfaces cabíveis, e a fundamentar mais uma dimensão do papel das ciências sociais na constituição do campo da saúde coletiva. Tornou possível arredondar a articulação entre "o" biológico e "o" social, tal como proposta quando da criação da Abrasco, e se afirmar ao mesmo tempo, haja vista o tema de abertura do primeiro encontro brasileiro de ciências sociais em saúde, "Políticas públicas na América Latina: dilemas e desafios"...

A partir desse momento, por exemplo, a relação entre padrões de mortalidade e desigualdade social (Leser \& Barbosa, 1972) ganha a conotação política que faltava; indicava-se que a abordagem teórico-metodológica necessária para a compreensão das perspectivas abertas requeria conhecimentos epistemológicos de todos os campos em articulação. Previdência e reforma sanitária, indústria de medicamentos, empresariamento da saúde e do trabalho médico, estudos socioepidemiológicos mais preocupados com embasamentos teóricos e metodológicos de ambos os campos são temas mais e mais presentes.

Esses desdobramentos são sobejamente conhecidos para os mais afetos às áreas consideradas. Se os registramos é para indicar ainda que com esta incorporação o campo cognitivo reveste-se de mais e mais amplitude e complexidade, o que torna possível ampliar críticas importantes sobre a redução mecanicista-positivista com que os modelos explicativos vinham sendo adotados na explicação daquelas relações, sem a necessária consideração dessa sua natureza complexa.

\section{Um mapeamento exploratório}

Comecemos visualizando o primeiro levantamento elaborado por García para a América Latina, para o período de 1950-1979, complementado por N unes (1992) com valores de 1980- 
1985 (D onnangelo, 1983) : é possível observar que, embora não sejam do mesmo montante, anunciam magnitudes semelhantes às dos 1 o e 2 o Congresso de Ciências Sociais em Saúde, como veremos (Tabela 1 ).

Para dar uma idéia dos eventos considerados, tentamos elaborar quadros contendo o tipo de evento, ano de realização e seu respectivo temário. É apenas uma forma de aproximação que não tem a pretensão de dar conta de todo 0 conteúdo abordado ao longo dos anos, mas tão somente visualizar o elenco de temas arrolados, considerando aqueles que se repetem nos diferentes eventos e aqueles suscitados por mudanças conjunturais mais específicas.

Tomamos como fontes os Anais desses eventos: 1o Encontro Brasileiro de Ciências Sociais em Saúde, realizado em 1993, na cidade de Belo H orizonte; 1o Congresso, realizado em Curitiba no ano de 1995; e 2o Congresso, ocorrido em São Paulo, em 1999. Para observarmos os eventos na perspectiva da relação constitutiva das ciências sociais no próprio campo da saúde coletiva, tentamos classificar as temáticas conforme as disciplinas que as compõem. Pois, enquanto 01 으 Encontro demarcava a constituição da área, no 10 Congresso o formato se aproximava de uma composição disciplinar que foi intencionalmente adotada no 20 Congresso, sempre contemplando o campo da saúde coletiva. M ais do que o número de trabalhos enviados para cada modalidade de apresentação, tomamos por critério os temas dos trabal hos apresentados tanto nas comunicações coordenadas como na forma de pôsteres; dado o formato do 1 o Encontro, os títulos dos trabal hos debatidos nas oficinas também foram considerados.

N ão há como comparar fontes e formatos tão diferentes. Enquanto no 1o Encontro a pro- dução mais significativa inseriu-se nas oficinas realizadas, havendo pequeno número de pôsteres, os Anais permitem deduzir que o elenco de temas é bastante semelhante aos do 10 e 20 Congressos, se cotejarmos com os registros sobre esses eventos. Por esses motivos, os quadros que apresentamos para comparar levam em conta apenas os respectivos temários e não 0 peso-importância que poderia ser atribuído a cada um deles através do número de trabalhos enviados a cada tema proposto. Pois, independentemente do número e da relevância dos trabalhos, a semelhança encontrada no elenco de temas é que nos permite melhor visualizar a produção no campo.

Enquanto as linhas apontam a cronologia e tipo de evento, as colunas apresentam uma forçada fragmentação do campo das ciências sociais a partir das disciplinas que o compõem. Aqui já encontramos uma dificuldade: fragmentar categorias temáticas transversais a essas disciplinas, como a sociologia e a política, ou a história e a antropologia, por exemplo, e todas com o processo saúde-doença, não deixa de constituir uma arbitrariedade.

Além disso, para analisar com mais rigor intelectual, teria sido necessário reler todos os resumos de maneira mais criteriosa; mas podemos arriscar algo sobre o 1o Encontro, ocorrido em 1993, e ver nos temas relacionados ("ensino", "a contribuição dos cientistas sociais" e "ciências sociais e a saúde mental") resquícios dos primórdios das interfaces já indicados anteriormente, não obstante o fato de se apresentarem de maneira bastante renovada em relação àquela influência da Escola de Chicago, sob a denominação de "ciências da conduta", quando a própria antropologia revestia-se de um caráter intervencionista. M as não deixa de consti-

\section{Tabela 1}

Distribuição das referências bibliográficas da Bibliografia latino-americana de ciências sociais aplicadas à saúde, segundo quatro categorias de temas e data da publicação. 1950-1985

\begin{tabular}{lccrrrr}
\hline Categorias & \multicolumn{7}{c}{ Ano da publicação } & & Total & $\%$ \\
\hline M edicina tradicional & 1950 & -1979 & 1980 & -1985 & 50 & 18,4 \\
Serviços de saúde & 445 & 26,8 & 61 & 5,6 & 1.000 & 36,3 \\
Processo saúde-doença & 507 & 30,5 & 493 & 45,4 & 887 & 32,2 \\
Formação de recursos humanos & 469 & 28,2 & 418 & 38,5 & 356 & 13,0 \\
\hline
\end{tabular}

Fontes: Período 1950-1979 - Bagley, Bravo, Gamboa, García: Bibliografia latinoamericana de ciencias sociales aplicadas a la salud. OPS, 1980.

Período 1980-1985 - Nunes: Bibliografia latino-americana de ciências sociais aplicadas à saúde, O pas, 1987. 
tuir um importante fato a ser considerado, tanto o tema como a grande quantidade de trabaIhos enviados e/ou apresentados nos eventos sob a rubrica "Educação" - estaráa aí o eixo mais "permanecente" da orientação da O pas e Escola de Chicago?

À primeira vista percebemos que o número de trabalhos apresentados nos dois congressos é muito próximo; onde então buscar as diferenças? No público inscrito em um e em outro, mesmo que daí não possamos tirar qualquer afirmação conclusiva: no 20 Congresso, embora não tivesse sido uma exigência, houve praticamente maior número de pessoas inscritas com trabalhos enviados do que para acompanhar as atividades do congresso. Fato digno de ser destacado é que são praticamente iguais o número de inscritos provenientes do campo das ciências sociais e o de pertencentes ao campo da saúde.

Se qui séssemos "personalizar" alguns desses temas, seria possível observar que são compostos por grupos de profissionais e técnicos que conseguiram se organizar social e politicamente (como no caso da "saúde mental", "educação e recursos humanos") e encaminhar propostas mais acabadas e amarradas para atividades "précongressos" e congressos: cursos, oficinas, comunicações coordenadas ou mesas (Quadro 1).

Ressaltemos que, à semelhança dos três temas do 1을 Encontro, nos 1ㅇ e 2 o Congressos 0 ensino de saúde coletiva está mais associado à formação de uma certa consciência sanitária. Em relação ao item referente à "comunicação", mais que recurso didático, desde o 10 Congresso enfatizava-se a comunicação de massa por meio de jornais, "mídias" impressa e falada, artes (teatro e dramaturgia), como estratégias de difusão de informações políticas. "Planejamento participativo", sintomaticamente, é um item que aparece mais explicitamente no 20 Congresso, a partir do qual podemos inferir o peso da implantação dos programas de gestão e capacitação de gestores e demais recursos humanos na atual conjuntura político-sanitária. Claro que além dos cursos a distância, a modernização dos meios técnico-informacionais também permitiu a utilização mais ágil destes recursos nas práticas de ensino.

Este tema compõe o item referente à "capacitação de RH", a mais destacada reminiscência dos primórdios de aproximações entre os campos considerados, se quisermos ser coerentes com a noção de historicidade apontada por Elias. Para tanto, é importante acrescentar informações históricas pouco referidas nos registros que tomamos por referência em item anterior, a respeito do momento e do patrocínio que promoveu a inserção das ciências sociais no campo da saúde.

Desde a década de 1920 assistíamos à incorporação da perspectiva médico-sanitária associada à formação de uma consciência sanitária. Já naquele momento a educação deveria cumprir um papel-chave, relacionando os princípios da saúde pública que deveriam ser implementados pelas administrações sanitárias.

\section{Quadro 1}

Temas de educação em saúde no 1o Encontro Brasileiro de Ciências Sociais e 1o e 2o Congresso de Ciências Sociais em Saúde

\begin{tabular}{lll}
\hline 10 Encontro (1993) & 10 Congresso (1995) & 2o Congresso (1999) \\
\hline Educação de usuários/programas & Educação de usuários/programas & Educação popular: \\
Capacitação de profissionais de saúde & Formação e treinamento de RH & - profissionalização \\
Ensino de ciências sociais & Véculos e estratégias de comunicação & - práticas alternativas \\
& Ensino de ciências sociais & - educação sanitária \\
& Formação médica/saúde coletiva: & Formação de RH: \\
& Graduação/RM/IDA & - gestores \\
& Tecnologias de ensino: & - agentes comunitários \\
& - material educativo & - educação e cidadania \\
& - tecnologias informacionais & - planejamento participativo \\
& • participação do aluno & Especialização profissional \\
& - avaliação & Formação docente reforma curricular \\
& & Recursos, instrumentos e estratégias \\
& & didático-pedagógicas
\end{tabular}


Conforme se sabe, o espraiamento dessa concepção muito se deveu à entrada da Fundação Rockefeller no Brasil, por ocasião de suas “expedições" à América do Sul a partir de 1913, quando decidiu ampliar suas atividades para o exterior. Labra ponta que no tocante à saúde pública, o programa da Rockefeller estava centralizado na International $\mathrm{H}$ ealth Board, inicialmente uma extensão direta da Sanitary Commission operando de forma independente, mas depois transformada numa di visão administrativa da Fundação.

Dentre os objetivos da "Santa M issão" (Labra, 1983), constavam os de firmar acordos com os governos locais para introduzir mudanças na organização e no ensino de saúde pública. Formou várias Comissões, sendo que a de 1915 teve por motivo explícito informar sua matriz sobre as condições vigentes nos países quanto a ensino e prática médicos, atenção hospitalar e dispensários, doenças endêmicas, serviços de saúde pública e progressos sanitários em geral (1983).

Ao voltar, em 1916, a Comissão mostrou às autoridades brasileiras o que considerava um completo atraso no que se referia à higiene, nas suas dimensões de saúde pública e medicina preventiva. Atribuía tal atraso à carência de conhecimento científico sólido para promover a higiene pessoal e pública; falta de treinamento mé dico em questão de higiene e espírito altruísta (ensino todo voltado para a clínica, o exercício privado e o lucro); falta de organizações sanitárias permanentes e abrangentes e de uma carreira de oficial de saúde que atraísse homens capacitados e interessados no apostolado da higiene (Gomes, 1992).

Às novas modalidades de assistência pública que vinham sendo delineadas deveria corresponder, pois, a criação de instituições que se propusessem a formar pessoal, desenvolver pesquisas e introduzir novas práticas em órgãos destinados à atenção. Essas foram as razões aventadas para a criação do Instituto de Higiene de São Paulo, em 1924, seguida da criação da Inspetoria de Educação Sanitária em 1925, inaugurando nova modalidade de assistência no Brasil. Neste sentido, além de combater a doença, o programa da Fundação oferecia uma oportunidade de carreira aos seus profissionais. E assim, desde aquele momento e por inspiração da própria Fundação Rockefeller, o ensino deveria estar norteado por um intercâmbio com outras áreas de conhecimento, em contato com as escolas de engenharia e com o ensino de ciências sociais e políticas, posto que era clara, nestes meios, a influência dos fatores sociais e econômicos nas questões de saúde pública.

De qualquer forma, no plano técnico-operacional, a perspectiva segundo a qual as práticas médico-sanitárias deveriam se dar em torno de postos de assistência e centros de saúde, orientou a reforma administrativa implantada na estrutura dos serviços sanitários de São Paulo, em 1925, a partir da qual seria desenvolvida uma nova forma educativa junto à população.

Estes apontamentos tornam ainda mais difícil considerar os campos em questão de maneira excludente, ainda mais se considerarmos que naquele momento não havia sequer formação em ciências sociais no Brasil, e, quando passou a existir, sua finalidade era inequívoca: a Escola Livre de Sociologia e Política de São Paulo deveria formar quadros para a administração pública, que, no campo da saúde e desde a 1a Guerra, estava amparada, nos auspícios da Fundação Rockefeller. A fundação da Universidade de São Paulo e com ela a Faculdade de Filosofia, Ciências e Letras, um ano mais tarde, buscou apoio nas correntes de pensamento e em intelectuais europeus. Em São Paulo pelo menos, este "campo científico" já trazia nas suas origens influências intelectuais marcadamente distintas. Esses acontecimentos só viriam confirmar, institucionalmente, a presença de grupos de interesse nem tão diferentes (uma vez que a USP também seria auspiciada por uma facção das elites paulistanas), mas com conseqüências importantes nas interfaces que se seguiram. A tarefa de reconstrução desses acontecimentos por meio das tessituras político-institucionais vem sendo realizada em vários ambientes acadêmicos e de pesquisa, mas continua sendo um grande desafio, sobretudo quando a ela agregamos a tentativa de visualização das interfaces construídas ao longo desse percurso histórico (Quadro 2).

No âmbito da antropologia, também podemos considerar permanências do passado nas temáticas voltadas para as práticas tradicionais apontadas no 10 Encontro temas que se estendem nos demais eventos, mas num contexto de maior diversidade e quantidade de resumos apresentados que destacam as racional idades embutidas nessas práticas e nas relativas à medicina oficial. É interessante observar que esta permanência já não se encontra no 20 Congresso, talvez devido ao fato de a própria convocação já indicar o temário dentro do qual os trabal hos deveriam ser encaminhados. V ale salientar também, que esta convocatória se deu a 
Quadro 2

Temas de antropologia no 1o Encontro Brasileiro de Ciências Sociais em Saúde e no 1o e 2o Congresso Brasileiro de Ciências Sociais em Saúde

\begin{tabular}{lll}
\hline 10 Encontro (1993) & 10 Congresso (1995) & 2o Congresso (1999) \\
\hline Práticas tradicionais & Práticas tradicionais e sistemas & Socioantropologia das doenças \\
Levantamentos etnográficos & terapêuticos: & Representações sobre doenças \\
Representações & - concepção de doença e racionalidades & - percepções: \\
Interacionismo simbólico & - representações e práticas alternativas & risco \\
Corpo & sobre saúde- doença & urgência \\
& Estudos de gênero & corpo \\
& & saúde-doença \\
& & - sujeitos na saúde e na doença
\end{tabular}

Fontes: Anais, 1994, 1995 e 1999.

partir de consulta prévia às instituições e profissionais da área de ciências sociais em saúde. Se, anteriormente, a preocupação era mais voltada para os "sistemas tradicionais", mais recentemente esse tema aparece sob a denominação de "práticas alternativas", com um tratamento metodológico distinto do modelo anterior. Quanto ao tema da "cultura e subjetividade", é importante lembrar mais uma vez a intenção prévia de compor uma mesa de caráter interdisciplinar, procurando promover um diálogo explícito entre as ciências sociais na sua interface com a epidemiologia ou com o campo da saúde (Quadro 3).

Como não poderia deixar de ser, o quadro 3 aponta o reflexo da implantação das políticas de saúde na atual conjuntura socioeconômica: das AIS ao SUS e a presença mais acentuada do PSF no 20 Congresso. Os temas relativos à descentralização, conselhos, participação, cidadania e movimentos sociais estão presentes nos três eventos, embora com mais destaque nos Congressos, pelos motivos apresentados - o mesmo pode ser dito quanto aos temas relativos às políticas e programas.

É possível depreender também que, do ponto de vista teórico, 0 apelo apresentado no 10 Encontro teve ressonâncias substantivas a partir de então, já na própria concepção-composição dos eventos subseqüentes; e, do ponto de vista metodológico, depreendemos que "estratégias de pesquisa" constituem tema destacado pela importância da interdisciplinaridade (Quadro 4).

É na interface com a epidemiologia que a dificuldade de fragmentação dos temas aparece com maior vigor: o próprio número de trabaIhos inscritos que se reportam à questão saúdedoença classificados como sendo desta área reproduzem as proporções da tabela 1 (N unes, 1987) - compondo mais de um $1 / 3$ dos trabaIhos enviados aos eventos considerados. Não foi possível deixar de incluir no quadro 4 temas de epidemiologia que também constituem objeto de estudo das ciências sociais e/ ou recebem tratamento desse campo, sendo que parte considerável deles foi proposta por profissionais do campo biomédico. Dentre as categorias próprias da epidemiologia, a de risco éa que se apresenta como mais plenamente transversal entre esses campos de conhecimento, percorrendo níveis também variáveis de complexidade conforme o campo considerado.

De forma geral, há temas que se repetem nos eventos considerados: "saúde da mulher" e "reprodução humana", por exemplo, são tópicos reiteradamente tratados, tendo a perspectiva de "gênero como ferramenta conceitual. 0 que chamou a aten ção no 20 Congresso, porém, foi a presença significativa de trabalhos que tratam sobre "reprodução humana" sob a ótica masculina, tanto em comunicação coordenada como em pôsteres. M uito embora temas relacionados às "representações sociais" e "construção social da doença" tenham sido abordados numa perspectiva teórica com forte apelo à etnometodologia e etnografia, a distinção entre "o" biológico e "o" social continua presente nos trabalhos. De qualquer modo, podemos ver aí significativas buscas de interfaces em direção à relação indivíduo-sociedade. 
Quadro 3

Temas de sociologia e política no 10 Encontro Brasileiro de Ciências Sociais em Saúde e no 10 e 2o Congresso de Ciências Sociais em Saúde.

\begin{tabular}{lll}
\hline 10 Encontro (1993) & 10 Congresso (1995) & 20 Congresso (1999) \\
\hline Implantação das AIS/Ações Básicas & Políticas de saúde na América Latina & Saúde e Reforma do Estado \\
deSaúde & SU S e reforma sanitária & Descentralização e formas de gestão \\
Descentralização/municipalização & Estado e política & Eqüidade, cidadania e exclusão \\
Participação popular & Relação público-privado & Ética e saúde \\
Estado, cidadania e movimentos sociais & Financiamento & Gênero e saúde \\
Políticas de saúde- questões & Descentralização - Conselhos de Saúde & Controle social e participação \\
teórico-metodológicas: & eG estão & Promoção de saúde eintersetorialidade \\
- crítica aos modelos totalizantes & Participação popular/Controle social & Avaliação - qualidade políticas \\
- políticas e sujeitos sociais & Cidadania e movimentos sociais & Programas/PSF \\
- ciências sociaise saúde coletiva & Avaliação - qualidade e serviços & Comunicação e redes de poder: \\
- gênero & Políticas e programas: & - discurso, linguagem \\
Ética e saúde/códigos e educação & - saúde mental & - veículos de difusão \\
História e políticas & - saúde do trabalhador & - redes de solidariedade emovimentos \\
Programas/ avaliação de impacto & - saúde da mulher/gênero & sociais \\
Saúde mental e interdisciplinaridade & Recursos humanos/profissões & Profissões: trajetórias, história e políticas \\
Profissões: sociologia e história & Ética e saúde & Questões teórico-metodológicas: \\
& História institucional & - triangulação metodológica, triangulação \\
& Questões teórico-metodológicas: & de temas \\
& - políticas sociais: concepções & - etnometodologia, etnografia
\end{tabular}

Fontes: Anais, 1994, 1995 e 1999.

\section{0 núcleo das tensões?}

Recentes editoriais do Informe Epidemiológico do SU S reeditam a questão polêmica que estamos tratando. Às voltas com a ampliação das contribuições da epidemiologia para a saúde coletiva, Barreto reforça mais uma vez que a investigação epidemiológica, tal como se caracteriza hoje, abarca o amplo espectro que vai da sociedade às moléculas, como uma das disciplinas mais bem preparadas para compreender o ser humano em suas múltiplas dimensões (2000); afirmação contraposta por M inayo, para quem a sociologia das ciências mostra que um dos grandes avan ços possíveis e necessários é o en contro de disciplinas (2000); e reposta por Goldbaum, lembrando que, como qualquer campo científico, elas [as ciências sociais] são também compostas por diferentes escolas de pensamento $e$ buscam verdades segundo suas lógicas respectivas (2001) conforme nós mesmas procuramos indicar a partir dos quadros que compõem as ciências sociais. M esmo afirmando não ter intenção de alimentar uma disjuntiva ou uma "com- petição" entre epidemiologia e ciências sociais e humanas em saúde, esse autor assume seu parti pris no embate nem tão aparente nesta antiga e cansativa querela.

Estão citados apenas para demonstrar, mais uma vez, quão insuperável pode ser a "contenda" quando os campos envolvidos se assumem como de fato o são: campos de forças e lutas. Lembremos a citação de Bourdieu sobre o que está em jogo nesta disputa: trata-se da busca de monopólio da autoridade científica, inseparável da capacidade técnica e do poder social. Admitamos que esta pode ser pelo menos uma contribuição das ciências sociais a ser levada em conta pelos epidemiologistas, o que não nos exime, como cientistas sociais, de repensarmos nossas formação e práticas nessa relação.

$N$ ão fomos formados para intervir no processo saúde-doença de maneira técnica-instrumental. N ossa reconhecida (por uns e outros) contribuição para o campo da saúde coletiva pode ser resumida no plano da razão, como bem aponta Villa N ova (1998), e nos põe numa situação pelo menos confortável, para não di- 
Quadro 4

Temas de epidemiologia no 1o Encontro Brasileiro de Ciências Sociais em Saúde e 1o e 2o Congresso de Ciências Sociais em Saúde

\begin{tabular}{|c|c|c|}
\hline 10 Encontro (1993) & 10 Congresso (1995) & 2o Congresso (1999) \\
\hline $\begin{array}{l}\text { Classe social, estratificação e condições } \\
\text { de vida } \\
\text { M apeamento e distribuição social } \\
\text { das doenças } \\
\text { Concepção e comportamento de risco } \\
\text { Representações sociais das doenças } \\
\text { Saúde da mulher, reprodução humana, } \\
\text { perspectiva de gênero } \\
\text { Desnutrição: diagnóstico e práticas } \\
\text { alimentares } \\
\text { Saúde e trabalho } \\
\text { Violência urbana } \\
\text { Saúde mental e exclusão } \\
\text { DST s/Aids } \\
\text { Concepção de saúde-doença } \\
\text { edeterminação social } \\
\text { Abordagens das ciências sociais } \\
\text { na epidemiologia: interfaces e } \\
\text { interdisciplinaridade } \\
\text { Questões teórico-metodológicas: crítica } \\
\text { aos modelos totalizantes de análise }\end{array}$ & $\begin{array}{l}\text { Territorialização e avaliação espacial } \\
\text { Espaço urbano e cidades saudáveis } \\
\text { Representações sociais de doenças } \\
\text { D oenças e estigma } \\
\text { Saúde da mulher, reprodução humana, } \\
\text { sexualidade e gênero } \\
\text { Saúdee trabalho: riscos, vigilância, } \\
\text { assistência e transformações organizacionais } \\
\text { Violência: ocorrência, gênese, categorias } \\
\text { de análise e multidisciplinaridade } \\
\text { Saúde mental: morbimortalidade e assistência } \\
\text { Aids: terapia, assistência eagenda de trabalho } \\
\text { Epidemiologia: abordagens } \\
\text { Questões teórico-metodológicas: } \\
\text { - amplificação social do risco } \\
\text { - inter e transdisciplinaridade }\end{array}$ & $\begin{array}{l}\text { Saúde da mulher e gênero } \\
\text { Reprodução humana, masculinidade e risco } \\
\text { Dimensão social dos perfis de } \\
\text { morbimortalidade: } \\
\text { - qualidade de vida } \\
\text { - eqüidade } \\
\text { - regionalização } \\
\text { Ambiente e saúde } \\
\text { Promoção de saúde e intersetorialidade } \\
\text { Construção e reprodução social da saúde } \\
\text { e da doença: } \\
\text { - saúde da perspectiva do sujeito } \\
\text { - papel social do medicamento } \\
\text { Violência: manifestações em segmentos } \\
\text { sociais } \\
\text { Saúde etrabalho: } \\
\text { - morbimortalidade } \\
\text { - reestruturação produtiva e risco, } \\
\text { - assistência } \\
\text { Migração e doença } \\
\text { Família, ciclos de vida e saúde } \\
\text { Estratégias térico-metodológicas da } \\
\text { pesquisa em saúde: interdisciplinaridade; } \\
\text { etnoepidemiologia }\end{array}$ \\
\hline
\end{tabular}

Fontes: Anais, 1994, 1995, 1999.

zer cômoda: qualquer insucesso nesse plano não nos éimputado. No entanto, insistimos em compartilhar um campo que é ao mesmo tempo de conhecimentos e práticas e, por esta insistência, devemos também ser responsabilizados, por que não? I gnorar ou negar essas interfaces, reivindicando autonomia de conhecimento para qualquer campo ou disciplina, significa desconsiderar a própria história - e já temos muita produção intelectual sobre esta matéria, de como se processa 0 acúmulo/ruptura de conhecimento socialmente produzido. Se não cumpriram a primeira finalidade que nos propusemos, os quadros apresentados dão idéia da amplitude de temas abarcados pelo campo das ciências sociais em saúde - alguma disciplina ou campo de conhecimento estaria autorizado a reivindicar a reflexão de todos el es autonomamente?

Além disso, considerar os sujeitos da ação social significa assumir o psiquismo como mais uma força que move em direção à manuten ção de posições na rede humana, apontado através de Elias (1994), inclusive quando se reivindica qualquer tipo de monopólio. 0 fato de essas questões estarem sendo postas neste momento já é indicativo de resposta - a criação de uma Associação Brasileira de Pós-Graduação em Saúde Coletiva, além de buscar congregar interesses e identidades, objetivo das associações em geral, muito contribuiu para o debate dessas questões, debate tanto mais rico quanto mais ampliado entre campos de conhecimento.

A própria Abrasco vem se encarregando de promover essas interfaces nos congressos e encontros que realiza, publicizando e envolvendo maior número de interessados. Como associação também defende interesses de seus associados e "simpatizantes", e a ela podemos atribuir a própria expansão das áreas envolvidas, na medida em que organiza e normatiza critérios para essa expansão nos cursos de pós-graduação, e defende os interesses da área nos fóruns em que se faz necessário. Esse é o papel de qualquer associação. M as, ao se instituir, catalisa não só interesses comuns como as tensões que os impregnam - só que essa já é uma outra história! 


\section{Referências bibliográficas}

Barreto M 2000. Informe Epidemiológico do SU S 9(3), juIho-agosto-setembro. M inistério da Saúde, Brasília

Bateson G 1986. M ente e natureza - a unidade necessária. Livraria Francisco Alves Editora, Rio de Janeiro.

Bodstein R 1992. Ciências sociais e saúde coletiva: novas questões, novas Abordagens. Cadernos de Saúde Pública 8(2):140-149.

Canesqui AM 1998. As ciências sociais e saúde no Brasil: três décadas de ensino e pesquisa. Ciência \& Saúde Coletiva III(1):131-168.

Consorte JG 1984. 0 ensino de antropologia na área médica: a experiência de Sorocaba. Trabalho apresentado à XIV Reunião da ABA, Brasília, abril/ns.

Donnangelo M CF 1983. A pesquisa na área da saúde coletiva no Brasil - a década de 70, pp. 19-35. In Ensino de saúde pública e medicina preventiva e social no Brasil. Abrasco, Rio de Janeiro.

Goldbaun M 2001. Informe Epidemiológico do SUS (10) 1 janeiro-fevereiro-março. M inistério da Saúde, Brasília.

Gomes M HA 1992. Tradição e progresso técnico. A medicina e o ensino médico na Escola Paulista de M edicina. Dissertação de mestrado em ciências sociais (concentração Antropologia) PUC - São Paulo, 144pp.

Kuhn TS 1989. A tensão essencial. Edições 70, Lisboa.

Labra M E 1985. 0 movimento sanitarista nos anos 30. Da conexão sanitária internacional à especialização em saúde pública no Brasil. Dissertação de mestrado. Escola Brasileira de Adminstração Pública. Rio de Janeiro, 156pp.
Leser WP \& Barbosa V 1972. Relacionamento de certas características populacionais com a mortalidade infantil no município de São Paulo de 1950 a 1970. Problemas Brasileiros 10:17-30.

Limongi F 1989. M entores e clientelas da U niversidade de São Paulo, pp. 229 e 226. In S M iceli (org.). A história das ciências sociais no Brasil. Vértice/IDESP, São Paulo.

M arsiglia RM G \& Spinelli SP 1995. As ciências sociais em saúde e o ensino, pp. 123-132. In AM Canesqui (org.). Dilemas e desafios das ciências sociais na saúde coletiva. Hucitec, São Paulo.

M inayo M CS. Informe Epidemiológico do SUS (9)4 outubro-novembro-dezembro/2000.

M inayo M CS 1997. Pós-graduação em saúde coletiva: um projeto em construção, pp. 53-71. Ciências Sociais \& Saúde Coletiva II (1/2).

Nunes ED 1992. As ciências sociais em saúde na América Latina, pp. 25-44. In AWP Spinola (org.). Pesquisa social em saúde. Editora Cortez, São Paulo.

N unes ED 1995. As ciências sociais e a saúde - o pensamento recente de al guns pesquisadores, 53-62. In AM Canesqui (org.). Dilemas e desafios das ciências sociais na saúde coletiva. Hucitec, São Paulo.

Pierson D (org.) 1948. Estudos de ecologia humana. Tomo I de Leituras de Sociologia e Antropologia Social. Livraria M artins Editora, São Paulo.

Villa N ova S 1998. D onald Pierson ea Escola de Chicago na Sociologia Brasileira: entre humanistas e messiânicos. Vega ed., Lisboa.

Artigo apresentado em 18/11/2002

Aprovado em 17/12/2002

Versão final apresentada em14/2/2003 